\title{
Comparative study of catalytic systems formed by palladium and acyl substituted imidazolium salts
}

\author{
Patricia Gisbert, ${ }^{[a]}$ Paz Trillo, ${ }^{[a][b]}$ and Isidro M. Pastor*[a] \\ [a] P. Gisbert, Dr. P. Trillo, Dr. I. M. Pastor \\ Organic Chemistry Dpt. and Instituto de Síntesis Orgánica (ISO) \\ University of Alicante \\ Apdo. 99, 03080, Alicante (Spain) \\ E-mail: patricia.gisbert@ua.es, paz.trillo@ua.es, ipastor@ua.es \\ https://www.mendeley.com/profiles/isidro-m-pastor/ \\ ORCID: orcid.org/0000-0002-8271-0641 (I. M. Pastor) \\ [b] Dr. P. Trillo (current address) \\ Chemistry Dpt., University of Umeå \\ 90187, Umeå (Sweden) \\ E-mail: paz.trillo@umu.se \\ ORCID: orcid.org/0000-0001-9540-630X (P. Trillo)
}

\begin{abstract}
Amino amides, which are readily accessible from amino acids, were used in the preparation of both monoamido and diamido functionalized imidazolium salts in very straightforward protocols. Different catalytic systems formed with palladium(II) acetate and acyl functionalized imidazolium salts were tested in the Matsuda-Heck reaction. The comparative study revealed that the presence of one carbamoyl moiety in the $\mathrm{N}$-heterocyclic carbene precursor is more beneficial during the catalytic process. Thus, better activity was observed with the catalytic system formed using the monoamido substituted salt $\mathbf{4 a}$ in a 1:1 metal/ligand ratio. Moreover, this fact was evidenced by means of UV/vis studies.
\end{abstract}

\section{Introduction}

Matsuda introduced the use of arenediazonium salts in the coupling with alkenes in 1977, ${ }^{[1]}$ expanding the versatility of the olefin arylation catalyzed by palladium described by Heck. Since that time, the Matsuda-Heck reaction (Scheme 1) has become an alternative in this type of couplings. ${ }^{[2]}$ This coupling reaction can be performed using a palladium salt in the absence of any additive. Although, the use of ligands in the Matsuda-Heck $(\mathrm{MH})$ reaction may help stabilize the species involved in the catalytic cycle. Indeed, carbene, macrocyclic olefin and thiourea derivatives have been described as capable ligands in the $\mathrm{MH}$ reaction. ${ }^{[2-3]}$ Thus, $\mathrm{MH}$ coupling reaction is interesting for comparing the ability during the catalysis of related catalytic systems.

$\mathrm{N}$-Heterocyclic carbenes (NHCs) have a wide variety of applications, including their use in homogeneous catalysis as ligands for transition metals, ${ }^{[4]}$ but they have also been used in materials science, ${ }^{[5]}$ organocatalysis, ${ }^{[6]}$ and the development of drugs such as antibacterial, cytotoxic or antitumor drugs. ${ }^{[7]} \mathrm{NHC}$ are usually prepared from the corresponding azolium salts, being imidazolium derivatives the most employed. The presence of a basic transition metal precursor allows the formation in situ of the $\mathrm{N}$-heterocyclic carbene starting from the corresponding imidazolium salt. ${ }^{[8]}$ Moreover, the introduction of functional groups in the substituents of the adjacent nitrogens is useful since it can provide versatility to these type of systems. Among the functional groups, acid derivatives, such as amides, are of interest since they can help during the catalytic process acting as labile ligands. The ability of the carbamoyl group to aid during the catalytic process may be better than other related functional groups (i.e. carboxylic acids and esters). Transition metal complexes with monoamido ${ }^{[9]}$ and diamido functionalized ${ }^{[10]} \mathrm{NHC}$ ligands have been described, being also evaluated their catalytic activity. Nevertheless, there is a lack of comparison with other related catalytic systems.

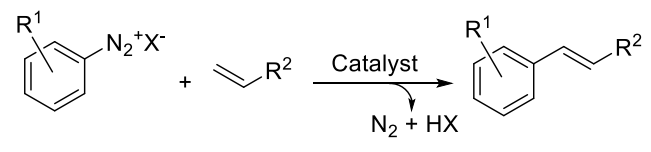

Scheme 1. General equation for the Matsuda-Heck reaction.

The development of catalytic systems is of significance due to the importance of finding sustainable processes. As a result, we have reported the development of homogeneous ${ }^{[89]}$ and heterogeneous catalytic systems using imidazolium derivatives ${ }^{[11]}$ Our aim is exploring the ability of carbamoyl functionalized imidazolium salts during a catalytic process, such as the Matsuda-Heck reaction, and comparing it with other carboxy-derivatives. Our interest also dwells in preparing the imidazolium salts with amido substituents starting from the corresponding $\alpha$-amino amides, which are readily available from the $\alpha$-amino acids (Figure 1 ). 


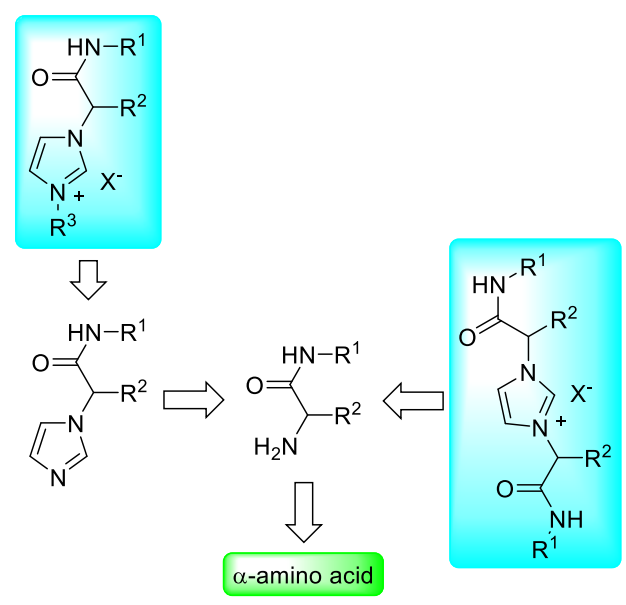

Figure 1. Approach to the carbamoyl functionalized imidazolium salts.

\section{Results and Discussion}

\section{Synthesis of functionalized imidazolium salts.}

According to our synthetic plan, we considered the preparation of $\alpha$-amino amides as a key step in the approach to imidazolium salts functionalized with a carbamoyl group (Figure 1). First, we performed the protection of the amino group in glycine. Then, $\mathrm{N}$ protected glycine was coupled with aniline and phenylmethylamine using a well-established protocol giving compounds $\mathbf{1}$ with high yield (Scheme 2). ${ }^{[12]}$ Then, deprotection of the amino group gave the corresponding a-amino amides 2 . Different methods were tried for cleaving the tert-butoxycarbonyl group, such as $\mathrm{HCl}(4 \mathrm{M})$ solution in dioxane ${ }^{[13]}$ or a mixture of $\mathrm{TFA} / \mathrm{H}_{2} \mathrm{O}(95: 5),{ }^{[14]}$ with partial achievement of the desired product. However, treatment of 1 with a mixture $(50 \% \mathrm{v} / \mathrm{v})$ of $\mathrm{HCl}(3 \mathrm{M}$, aq. solution) and methanol gave deprotection of the amino group quantitatively (Scheme 2). The procedure allowed the preparation of other amino amide derivatives from glycine [such as $\mathrm{N}$-2-amino-(2-hydroxy-1,1-dimethylethyl)acetamide (2c)] and L-valine [such as (2S)- $\mathrm{N}$-2-amino[(1S)-(1-hydroxymethyl-2-methylpropyl)-3-methyl]butanamide (2e) and (2S)-N-2-amino-(2-hydroxy-1,1-dimethylethyl)-3methylbutanamide (2f)], (see Supporting Information).

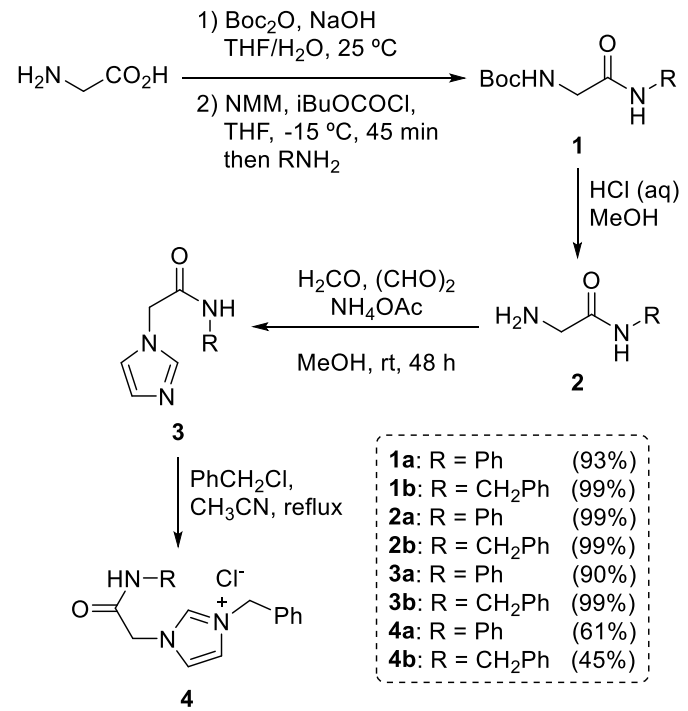

Scheme 2. Synthesis of amino amides 2, carbamoyl functionalized imidazoles $\mathbf{3}$ and the corresponding imidazolium chlorides 4

Having the amino amides in hand, the most straightforward imidazole synthesis involves the formation of three bonds starting from a dicarbonyl compound, an aldehyde and ammonia to react together with the amino amide. ${ }^{[15]}$ This procedure may present certain limitations due to the formation of a mixture of products, in particular when carrying out the reaction at high temperatures. Regrettably, the multicomponent reaction of formaldehyde, glyoxal, ammonium acetate and the amino amide 2 a produced only, after $3 \mathrm{~h}$ of refluxing, the 1 -phenylpyrazin-2-one from the coupling of $\mathbf{2 a}$ and glyoxal (see Supporting Information). Interestingly, we 
found that the formation of the desired imidazole derivative could be obtained exclusively by lowering the temperature. Indeed, imidazole derivatives $\mathbf{3}$ were isolated with excellent yields performing the reaction at room temperature, although longer times were needed (Scheme 2). The reaction with $\mathbf{2 a}$, formaldehyde, glyoxal and ammonium acetate was carried out in methanol at room temperature for $48 \mathrm{~h}$ producing the expected imidazole with $90 \%$ yield (Scheme 2 ). The same procedure was applied to compound $\mathbf{2 b}$ giving quantitatively the imidazole $\mathbf{3 b}$. Finally, the corresponding imidazolium salts $\mathbf{4}$ were prepared by reacting the compounds $\mathbf{3}$ with benzyl chloride, the salts $\mathbf{4}$ being isolated as solids upon recrystallization in moderate yields (Scheme 2).

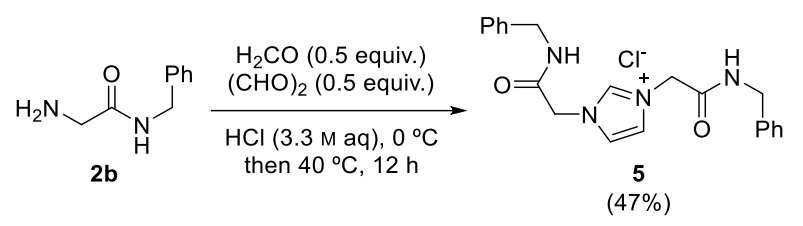

Scheme 3. Synthesis of dicarbamoyl functionalized imidazolium chloride 5.

Next, it was considered of interest, as discussed above, the preparation of imidazolium salt $\mathbf{5}$ bearing two carbamoyl moieties. To carry out the preparation, two equivalents of amino amide $\mathbf{2 b}$ were reacted with glyoxal and formaldehyde in the presence of hydrochloric acid, the compound 5 being isolated in $47 \%$ yield (Scheme 3 ).

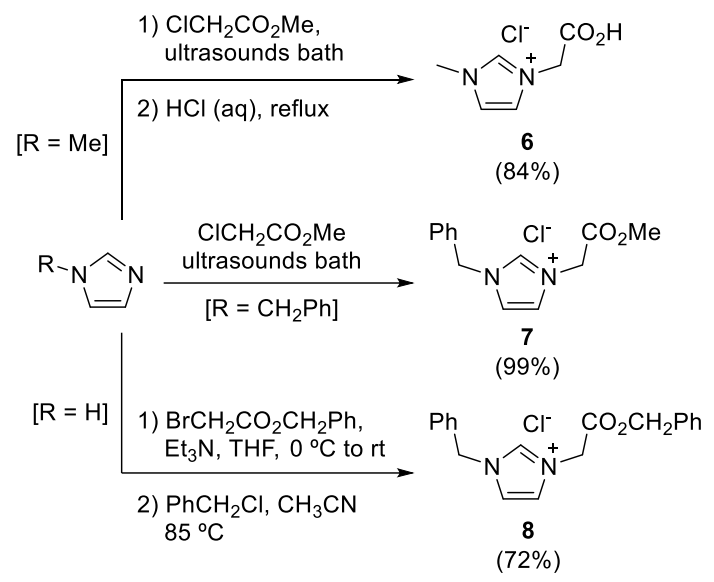

Scheme 4. Synthesis of carboxy functionalized imidazolium chlorides 6-8.

At this point, we found it interesting to include analogous monocarboxy and dicarboxy functionalized imidazolium salts in the study by way of comparison. Following this idea, both ester and carboxylic acid moieties were included for evaluation. The synthesis of the monocarboxy functionalized imidazolium chloride 6 was carried out by reaction between 1-methylimidazole and methyl chloroacetate followed by acidic cleavage of the ester moiety (Scheme 4). The imidazolium chloride 6 was isolated in $84 \%$ yield. Similar imidazole quaternization from 1-benzylimidazole allowed the preparation of imidazolium chloride 7 in quantitative yield (Scheme 4). Additionally, imidazole was subsequently reacted with benzyl 2-bromoacetate and benzyl chloride to obtain functionalized imidazolium salt 8 (Scheme 4).

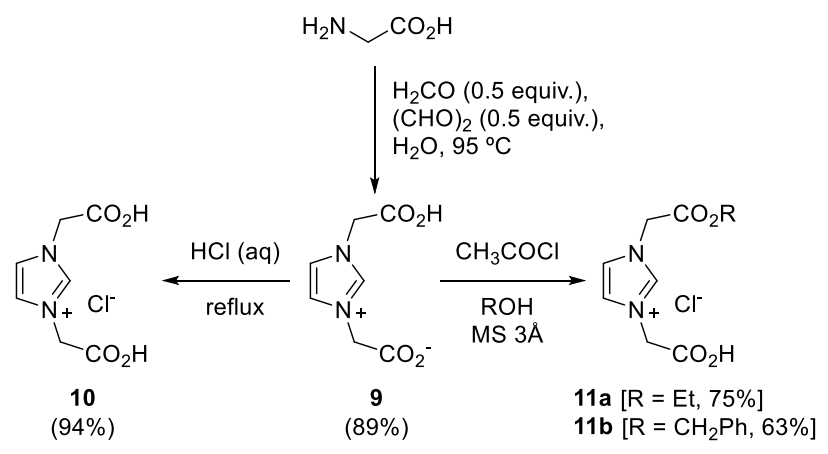

Scheme 5. Synthesis of dicarboxy functionalized imidazolium chlorides $\mathbf{1 0}$ and $\mathbf{1 1 .}$ 
Regarding difunctionalized imidazole derivative, the synthesis of the zwitterion 1,3-bis(carboxymethyl)imidazole (bcmim, 9) was performed by a multicomponent reaction between glycine and aqueous solutions of glyoxal and formaldehyde, isolating product $\mathbf{9}$ in $89 \%$ yield (Scheme 5). ${ }^{[11 a]}$ Subsequently, this zwitterion was transformed almost quantitatively into the corresponding imidazolium chloride 10 by acidic treatment (Scheme 5). Furthermore, imidazolium salts $\mathbf{1 1}$ bearing simultaneously both alkoxycarbonyl and carboxy moieties were easily prepared by reaction of zwitterion 9 with an alcohol in the presence of acetyl chloride (Scheme 5).

\section{Catalytic activity.}

The use of the NHC ligand in the Matsuda-Heck reaction, as discussed above, may help to stabilize the species involved in the catalytic cycle. Therefore, we studied the effect of mono and difunctionalized imidazolium salts as precursors of ligands for palladium in this reaction. The coupling of ethyl acrylate with a benzenediazonium salt was taken as model reaction to evaluate the different catalytic systems. The parameters in Table 1 were selected in order to study their influence in the catalytic process. The following considerations were taken into account. (1) Imidazolium salt: Different imidazolium salts were considered to study the influence of the amido and carboxyl groups, both monosubstituted and disubstituted, thus the imidazolium salts 4a, 5, 6 and 10 were chosen, at the outset, to cover the ligand diversity in this work. (2) Catalytic system: Based on previous studies in which differences were observed according to the catalytic system used, ${ }^{[8 g},{ }^{16]}$ three levels were chosen, i.e. $\mathrm{Pd}(\mathrm{OAc})_{2}(1 \mathrm{~mol}-\%), \mathrm{Pd}(\mathrm{OAc})_{2}$ and imidazolium salt ( $1 \mathrm{~mol}-\%$ each), and $\mathrm{Pd}(\mathrm{OAc})_{2}(1 \mathrm{~mol}-\%)$ and imidazolium salt $(2 \mathrm{~mol}-\%)$. (3) Base: This parameter was included due to the presence of substituents in the imidazolium salts with acid-base properties, although the role of the base is still not clear in this transformation and in preliminary studies the influence of the base (i.e. NaOAc) appears to be detrimental. ${ }^{[16]}(4)$ Benzenediazonium salt: Three salts were chosen in order to study the influence of the substituent in the substrate in terms of reactivity.

\begin{tabular}{l} 
Table 1. Parameters and levels for the design of experiments approach. \\
\hline \multicolumn{5}{c}{ Parameter } \\
\hline
\end{tabular}

For the comparative study, we conducted several experiments in order to obtain valuable information concerning the selected parameters employing a minimum set of assays. The yield obtained for the coupling product was correlated with the activity of the catalytic system. The greater the activity, the higher the yield. To carry out the different experiments, the various benzenediazonium salts were reacted with ethyl acrylate under the conditions described in Table 2 . The reactions were performed at $40^{\circ} \mathrm{C}$ according to beforehand reported studies. ${ }^{[16]}$ Although, formerly studies also showed that tetrahydrofuran (THF) and ethanol (EtOH), under certain reaction conditions, are good solvents, we considered different solvents before starting the comparative study (see Supporting Information). THF was selected to carry out the comparative study. 
Table 2. Catalytic activity of imidazolium salts $\mathbf{4 a}, \mathbf{5}, \mathbf{6}$ and 10 in the MatsudaHeck reaction. ${ }^{[a]}$

\begin{tabular}{|c|c|c|c|c|c|}
\hline & $\mathrm{BF}_{2}^{\mathrm{BF}_{4}^{-}}+$ & $\frac{\mathrm{Pc}}{\mathrm{imi}}$ & $\begin{array}{c}\mathrm{Pd}(\mathrm{OAc})_{2}(1 \mathrm{~mol}-\%) \\
\text { imidazolium salt, base } \\
\text { THF, } 40^{\circ} \mathrm{C}, 3 \mathrm{~h}\end{array}$ & \multicolumn{2}{|c|}{$12-14$} \\
\hline & \multirow[b]{2}{*}{$\begin{array}{l}\text { Ratio } \\
\text { (Pd:Salt) }\end{array}$} & \multirow[b]{2}{*}{$\begin{array}{l}\mathrm{NaOAc} \\
\text { (equiv.) }\end{array}$} & \multicolumn{3}{|c|}{ Yield $(\%)^{[b]}$} \\
\hline Salt & & & $\begin{array}{l}12 \\
(R=H)\end{array}$ & $\begin{array}{l}13 \\
(\mathrm{R}=\mathrm{OMe})\end{array}$ & $\begin{array}{l}14 \\
(\mathrm{R}=\mathrm{COMe})\end{array}$ \\
\hline No salt & $1: 0$ & 0 & 48 & 11 & 48 \\
\hline \multirow[t]{4}{*}{$4 a$} & $1: 1$ & 0 & 89 & 36 & $>99$ \\
\hline & & 1 & 4 & $<1$ & 16 \\
\hline & $1: 2$ & 0 & 30 & 1 & 90 \\
\hline & & 1 & 7 & 6 & 2 \\
\hline \multirow[t]{4}{*}{5} & $1: 1$ & 0 & 78 & 22 & 69 \\
\hline & & 1 & 4 & 0 & 2 \\
\hline & $1: 2$ & 0 & 38 & 16 & 26 \\
\hline & & 1 & 56 & 10 & 2 \\
\hline \multirow[t]{4}{*}{6} & $1: 1$ & 0 & 65 & 9 & $>99$ \\
\hline & & 1 & 5 & 0 & 2 \\
\hline & $1: 2$ & 0 & 76 & 26 & 59 \\
\hline & & 1 & 5 & 2 & 2 \\
\hline \multirow[t]{4}{*}{10} & $1: 1$ & 0 & 54 & 41 & $>99$ \\
\hline & & 1 & 2 & 4 & 1 \\
\hline & $1: 2$ & 0 & 45 & 21 & 75 \\
\hline & & 1 & 1 & 0 & 2 \\
\hline
\end{tabular}

[a] Reaction conditions: benzenediazonium tetrafluoroborate $(1 \mathrm{mmol})$, ethyl acrylate $(2 \mathrm{mmol}), \mathrm{Pd}(\mathrm{OAc})_{2}(0.01 \mathrm{mmol})$, imidazolium salt $(0,0.01$ or 0.02 $\mathrm{mmol}), \mathrm{NaOAc}(0$ or $1 \mathrm{mmol}), \operatorname{THF}(0.5 \mathrm{~mL}), 40 \stackrel{\circ}{\circ}, 3 \mathrm{~h}$. [b] Yield obtained using GC analysis, employing mesitylene as internal standard.

Analyzing the results obtained, in general, there is enough dispersion (see Supporting Information) and the optimal conditions in each case could be dependent on various factors apart from the catalytic system. However, this analysis clearly revealed that the use of base was detrimental to the reaction (Table 2 and Supporting Information), resulting in low yields regardless of the remaining variables. We assumed that the experiments carried out in the presence of base are affecting the statistical analysis, not being able to see trends of the other factors. Therefore, the results were analyzed again excluding those performed in the presence of base, a trend for the different parameters being observed (Figure 2). The use of two equivalents of imidazolium salt with respect to palladium provided worse results (Figure 2a), so it can be assumed that the most active catalytic species has only one NHC ligand coordinated to the metal centre. Thus, the use of an imidazolium salt, in the proper ratio to palladium, has a positive effect on the catalytic activity for the assayed reaction conditions (Table 2). With respect of the imidazolium salts, in general, the experiments carried out using monosubstituted systems (i.e. 4a and $\mathbf{6}$ ) provided better results in comparison with imidazolium salts bearing two functional groups, such as $\mathbf{5}$ and $\mathbf{1 0}$ (Figure $\mathbf{2 b}$ ). In addition, the analysis of the results according to the formed products gave rise to the predicted trend (Figure 2c). As expected, benzenediazonium salts bearing electron-donating groups gave worse results than those without substituent and with electron-withdrawing groups. 

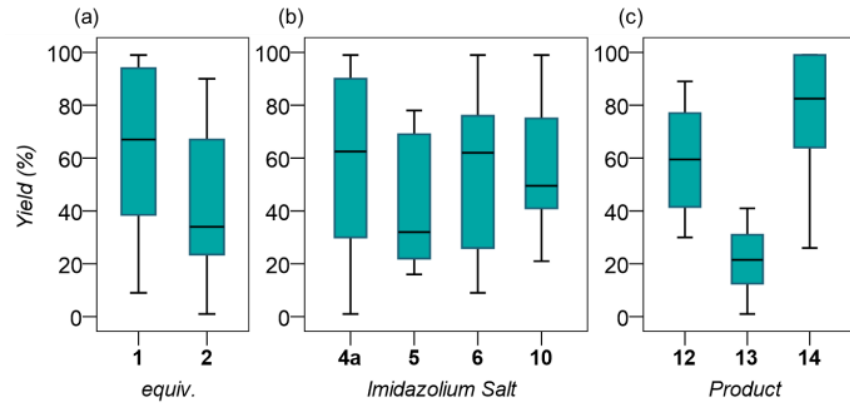

Figure 2. Boxplot of experimental data from Table 2, excluding the experiments with base, as function of (a) imidazolium salt equivalents, (b) imidazolium salt employed and (c) product obtained.

A new set of experiments including other imidazolium salts (i.e. $\mathbf{4 b}, \mathbf{7}, \mathbf{8}, \mathbf{1 1 a}$ and $\mathbf{1 1} \mathbf{b}$ ) was carried out in order to complete the study, the results being presented in Table 3 . The analysis of the results from both sets of experiments demonstrated that the use of 1 equivalent of imidazolium salt improves the outcome of the reaction (Figure 3), giving probably a more active catalytic species. The use of higher amounts of imidazolium salt (2 equiv.) can be beneficial or not depending on other factors (Figure 3 ). Essentially, we observed that imidazolium salt $\mathbf{4 a}$ bearing one amide functional group provided the best catalytic activity when comparing with the rest of imidazolium salts in this study (Figure 4). The substituent in the nitrogen of the amide is also a factor to consider, the anilide type in $\mathbf{4 a}$ being better. Regarding carboxy functionalized imidazolium salts, monosubstituted salt 6 provides a more active catalytic system than disubstituted one, albeit catalytic system based on salt $\mathbf{1 0}$ depends less on other factors giving lesser results dispersion (Figure 4). The study revealed also that the presence of an ester moiety in the imidazolium salt is not positive for the catalytic activity (Figure 4, salts 7, 8, 11a and 11b).

Table 3. Catalytic activity of imidazolium salts $4 \mathrm{~b}, \mathbf{7}, \mathbf{8}, \mathbf{1 1 a}$ and $\mathbf{1 1 b}$ in the Matsuda-Heck reaction. ${ }^{[a]}$

\begin{tabular}{|c|c|c|c|c|}
\hline \multirow[b]{3}{*}{ Salt } & \multirow[b]{3}{*}{ Ratio (Pd:Salt) } & \multicolumn{2}{|c|}{$\begin{array}{c}\mathrm{Pd}(\mathrm{OAc})_{2}(1 \mathrm{~mol}-\%) \\
\text { imidazolium salt } \\
\text { THF, } 40^{\circ} \mathrm{C}, 3 \mathrm{~h}\end{array}$} & $12-14$ \\
\hline & & \multicolumn{3}{|c|}{ Yield (\%) $)^{[\mathrm{b}]}$} \\
\hline & & $12(R=H)$ & $13(\mathrm{R}=\mathrm{OMe})$ & $14(\mathrm{R}=\mathrm{COMe})$ \\
\hline \multirow[t]{2}{*}{$4 b$} & $1: 1$ & 50 & 20 & 80 \\
\hline & $1: 2$ & 19 & 3 & 21 \\
\hline \multirow[t]{2}{*}{7} & $1: 1$ & 54 & 5 & 50 \\
\hline & $1: 2$ & 47 & 8 & 23 \\
\hline \multirow[t]{2}{*}{8} & $1: 1$ & 57 & 2 & 52 \\
\hline & $1: 2$ & 45 & 26 & 65 \\
\hline \multirow[t]{2}{*}{ 11a } & 1:1 & 65 & 25 & 63 \\
\hline & $1: 2$ & 44 & 3 & 33 \\
\hline \multirow[t]{2}{*}{$11 b$} & $1: 1$ & 74 & $<1$ & 58 \\
\hline & $1: 2$ & 60 & 6 & 58 \\
\hline
\end{tabular}

[a] Reaction conditions: benzenediazonium tetrafluoroborate $(1 \mathrm{mmol})$, ethyl acrylate $(2 \mathrm{mmol}), \mathrm{Pd}(\mathrm{OAc})_{2}(0.005 \mathrm{mmol})$, imidazolium salt $(0.01$ or 0.02 $\mathrm{mmol})$, THF $(0.5 \mathrm{~mL}), 40^{\circ} \mathrm{C}, 3 \mathrm{~h}$. [b] Yield obtained using $\mathrm{GC}$ analysis, employing mesitylene as internal standard. 


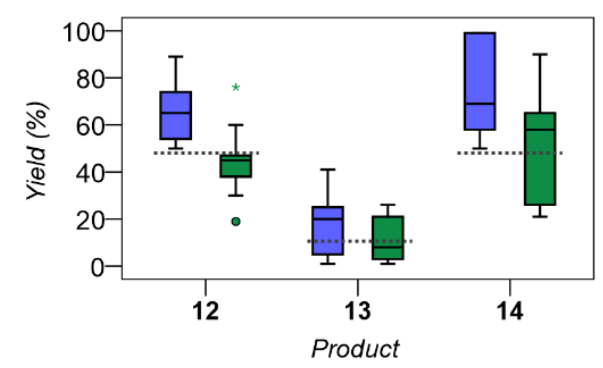

Figure 3. Boxplot of experimental data from Tables 2 and 3 , excluding the experiments with base, as function of the ratio Pd/imidazolium salt: 1 to 1 (blue), 1 to 2 (green). Dash line (...-) represents the reaction without imidazolium salt.

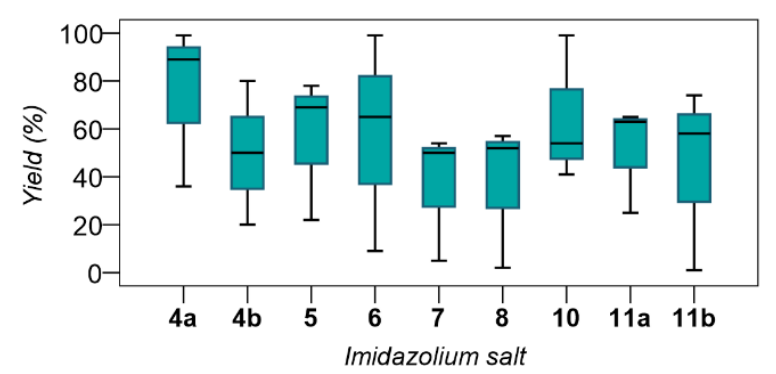

Figure 4. Boxplot of experimental data from Tables 2 and 3 with a Pd/imidazolium salt ratio of 1 to 1 as a function of the imidazolium salt.

Looking closely at the results using imidazolium salts with amide moieties, we found that there is almost no interaction between the amount of salt employed and the structure of the salt. Indeed, the lines run basically parallel in Figure 5. ${ }^{[17]}$ Thus, the catalytic species formed is similar regardless of the type of carbamoyl functionalized imidazolium salt, the salt 4 a forming the best catalytic system in a 1:1 ratio with palladium. In contrast, imidazolium salts bearing carboxy moieties did not behave following the same pattern, and the catalytic system formed could be different depending on the amount of salt employed (see Supporting Information). Consequently, the use of carbamoyl functionalized imidazolium salts resulted in the formation of steady catalytic systems. The decrease in the activity when using higher amount of imidazolium salt could be explained by the formation of less active (or nonactive) palladium species in equilibrium with the active monocarbene (NHC-Pd) complex, as previously reported for other $\mathrm{N}$ heterocyclic carbene ligands ${ }^{[18]}$ and also for phosphane ligands. ${ }^{[19]}$

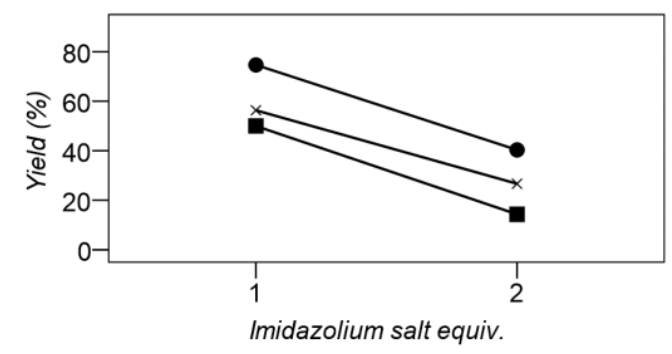

Figure 5. Interaction graph between Pd/imidazolium salt ratio and carbamoyl substituted imidazolium salts: $\mathbf{4 a}(\bullet), \mathbf{4 b}(\mathbf{\bullet})$ and $\mathbf{5}(\mathrm{x})$.

At this point, we carried out experimental UV/vis studies to evidence that the catalytic system, in solution, is formed by a $1: 1$ metal/ligand ratio when using salt $\mathbf{4 a}$. Thus, the spectrophotometric tritation (see Supporting Information) of acetonitrile solution $\left(2.5 \times 10^{-5} \mathrm{M}\right)$ of ligand $4 \mathrm{a}$ with increasing amounts of an acetonitrile solution of $\mathrm{Pd}(\mathrm{OAc})_{2}\left(5 \times 10^{-5} \mathrm{M}\right)$ confirmed the formation of a $1: 1$ metal/ligand complex. Representative spectra for the UV/vis studies are shown in Figure $6(\lambda=224$ and $246 \mathrm{~nm}) .{ }^{[20]} \mathrm{It}$ may be postulated that the presence of the carbamoyl group assists in the stabilization of the active catalytic species needing only a carbene ligand per metal center, which is distinctly different from NHC systems functionalized with hydroxyl moieties in which a 1:2 ratio metal/ligand is necessary. ${ }^{[8 g, 16]}$ 

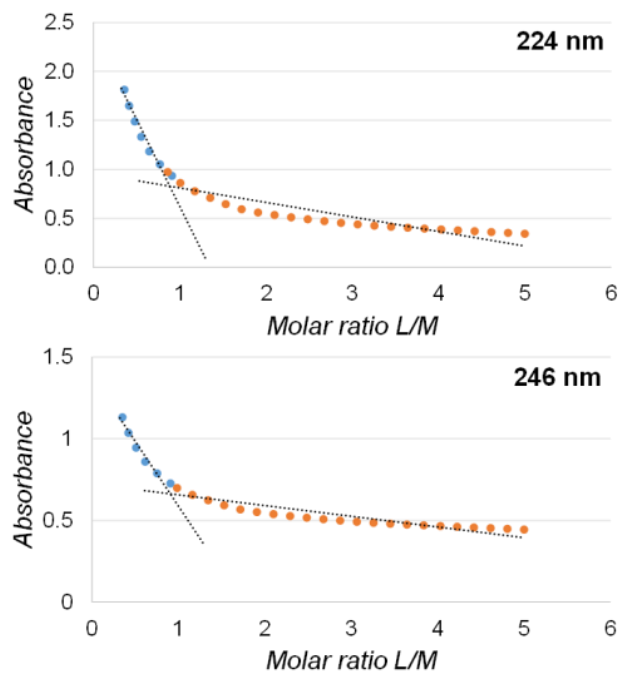

Figure 6. Representative UV/vis studies for the palladium complex of $\mathbf{4 a}$.

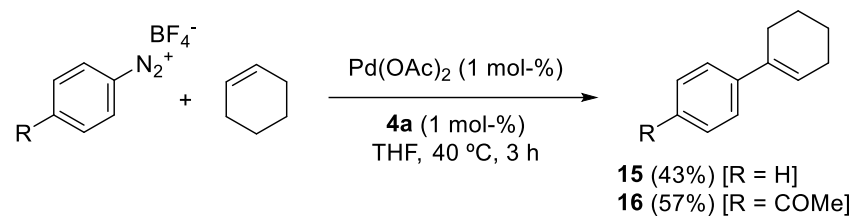

Scheme 6. Matsuda-Heck reaction conditions: benzenediazonium tetrafluoroborate ( $1 \mathrm{mmol})$, cyclohexene $(2 \mathrm{mmol}), \mathrm{Pd}(\mathrm{OAc}) 2(0.01 \mathrm{mmol}), 4 a(0.01 \mathrm{mmol})$, $\operatorname{THF}(0.5 \mathrm{~mL}), 40^{\circ} \mathrm{C}, 3 \mathrm{~h}$.

Finally, the reaction using 'unactivated' alkenes, ${ }^{[2 b]}$ such as cyclohexene, with the catalytic system using the salt $4 \mathbf{a}$ was tested. The corresponding 1-arylcyclohexenes $\mathbf{1 5}$ and $\mathbf{1 6}$ were obtained as a single isomer employing the studied reaction conditions (Scheme 6). The use of cyclic olefins usually produces the formation of the Heck products with the aryl group in the allylic or homoallylic position. The arylation at the vinylic position has been achieved with longer reaction times (24 h) in order to allow the isomerization to the conjugated product, ${ }^{[21]}$ or using N-heterocyclic carbenes. ${ }^{[16]}$ In our case, the use of electron-donating groups (i.e. methoxy) in the arenediazonium salt provided a mixture of products (Supporting Information).

\section{Conclusions}

To conclude, the synthesis of both monoamido and diamido functionalized imidazolium salts have been easily prepared from aamino amides by ring construction modulating the stoichiometry and reaction conditions. Moreover, the comparative study has proved that the carbamoyl group is performing better as additional labile ligand in N-heterocyclic carbenes in comparison with other carboxy substituents (such as carboxylic acids and esters). The catalytic system formed by a ratio 1:1 palladium/imidazolium salt gave the best results, employing monoamido substituted ligand precursors. In fact in solution, the formation of complex one-to-one has been evidenced by the UV/vis studies, as the preferred. Additionally, the use of carbamoyl functionalized imidazolium salts resulted in the formation of more regular catalytic systems, regardless to other factors. Furthermore, the catalytic system formed with palladium(II) acetate and salt $\mathbf{4 a}$ produced the arylation at the vinylic position of cyclohexene. Consequently, the catalytic system formed by $\mathbf{4 a}$ and palladium can be considered as a complementary alternative to the use of other ligands in this transformation.

\section{Experimental Section}

(See Supporting Information) 


\section{Acknowledgements}

\section{The Spanish Ministry (Ministerio de Economía y Competitividad CTQ2015-66624-P) and the University of Alicante (VIGROB-285) are gratefully acknowledged for financial support.}

Keywords: Matsuda-Heck reaction $• \mathrm{~N}$-heterocyclic carbene $\bullet$ palladium $\bullet$ functionalized imidazolium $•$ carbamoyl

[1] K. Kikukawa, T. Matsuda, Chem. Lett. 1977, 6, 159-162.

[2] (a) A. Roglans, A. Pla-Quintana, M. Moreno-Mañas, Chem. Rev. 2006, 106, 4622-4643; (b) J. G. Taylor, A. V. Moro, C. R. D. Correia, Eur. J. Org. Chem. 2011, 1403-1428.

[3] M. Yus, I. M. Pastor, Chem. Lett. 2013, 42, 94-108.

[4] (a) N-Heterocyclic carbenes: Effective tools for organometallic synthesis, S. P. Nolan ed., Wiley-VCH, Weinheim, 2014; (b) E. Levin, E. Ivry, C. E. Diesendruck, N. G. Lemcoff, Chem. Rev. 2015, 115, 4607-4692.

[5] (a) B. M. Neilson, A. G. Tennyson, C. W. Bielawski, J. Phys. Org. Chem. 2012, 25, 531-543; (b) R. Visbal, M. C. Gimeno, Chem. Soc. Rev. 2014, 43, 3551-3574; (c) V. Charra, P. d. Frémont, P. Braunstein, Coord. Chem. Rev. 2017, 341, 53-176; (d) N. Sinha, F. E. Hahn, Acc. Chem. Res. 2017, 50, 2167-2184.

[6] (a) S. J. Ryan, L. Candish, D. W. Lupton, Chem. Soc. Rev. 2013, 42, 4906-4917; (b) S. R. Yetra, A. Patra, A. T. Biju, Synthesis 2015, 47, 1357-1378 (c) W. C. Hartley, T. J. C. O'Riordan, A. D. Smith, Synthesis 2017, 49, 3303-3310.

[7] (a) K. M. Hindi, M. J. Panzner, C. L. Cannon, W. J. Youngs, Chem. Rev. 2009, 109, 3859-3884; (b) F. Cisnetti, A. Gautier, Angew. Chem., Int. Ed. 2013 52, 11976-11978; (c) S. A. Patil, S. A. Patil, R. Patil, R. S. Keri, S. Budagumpi, G. R. Balakrishna, M. Tacke, Future Med. Chem. 2015, 7, 1305-1333; (d) B. R. M. Lake, M. R. Chapman, C. E. Willans, Organomet. Chem. 2016, 40, 107-139; (e) W. Liu, R. Gust, Coord. Chem. Rev. 2016, $329,191-213$.

[8] (a) M. S. Viciu, F. K. Zinn, E. D. Stevens, S. P. Nolan, Organometallics 2003, 22, 3175-3177; (b) G. D. Frey, J. Schuetz, W. A. Hermann, J. Organomet Chem. 2006, 691, 2403-2408; (c) A. G. Goekce, M. E. Guenay, M. Ayguen, B. Cetinkaya, O. Buyukgungor, J. Coord. Chem. 2007, 60, 805-813; (d) S. Fantasia, S. P. Nolan, Chem. Eur. J. 2008, 14, 6987-6993; (e) S. Gulcemal, S. Kahraman, J.-C. Daran, E. Cetinkaya, B. Cetinkaya, J. Organomet. Chem. 2009, 694, 3580-3589; (f) I. Peñafiel, I. M. Pastor, M. Yus, M. A. Esteruelas, M. Oliván, Organometallics 2012, 31, 6154-6161; (g) A. Allegue, M. Albert-Soriano, I. M. Pastor, Appl. Organomet. Chem. 2015, 29, 624-632; (h) T. Bolaño, M. A. Esteruelas, M. P. Gay, E. Oñate, I. M. Pastor, M. Yus, Organometallics 2015, 34, 3902-3908; (i) D. J. Nelson, Eur. J. Inorg. Chem. 2015, 2012-2027.

[9] (a) Y.-C. Lin, H.-H. Hsueh, S. Kanne, L.-K. Chang, F.-C. Liu, I. J. B. Lin, Organometallics 2013, 32, 3859-3869; (b) A. Kumar, L. P. Bheeter, M. K. Gangwar, J.-B. Sortais, C. Darcel, P. Ghosh, J. Organomet. Chem. 2015, 786, 63-70; (c) S. Warsink, J. A. Venter, A. Roodt, J. Organomet. Chem. 2015 $775,195-201$.

[10] (a) R. Kamisue, S. Sakaguchi, J. Organomet. Chem. 2011, 696, 1910-1915; (b) K. V. Tan, J. L. Dutton, B. W. Skelton, D. J. D. Wilson, P. J. Barnard, Organometallics 2013, 32, 1913-1923

[11] (a) M. Albert-Soriano, I. M. Pastor, Eur. J. Org. Chem. 2016, 5180-5188; (b) P. Trillo, I. M. Pastor, Adv. Synth. Catal. 2016, 358, 2929-2939; (c) M. Albert-Soriano, P. Trillo, T. Soler, I. M. Pastor, Eur. J. Org. Chem. 2017, 10.1002/ejoc.201700990.

[12] I. M. Pastor, P. Västilä, H. Adolfsson, Chem. Eur. J. 2003, 9, 4031-4045.

[13] D. Almaşi, D. A. Alonso, C. Nájera, Adv. Synth. Catal. 2008, 350, 2467-2472.

[14] M. Paradis-Bas, M. Albert-Soriano, J. Tulla-Puche, F. Albericio, Org. Biomol. Chem. 2014, 12, 7194-7196.

[15] M. R. Grimmett, Imidazole and benzimidazole synthesis, Academic Press, London, 1997.

[16] I. Peñafiel, I. M. Pastor, M. Yus, Eur. J. Org. Chem. 2012, 3151-3156.

[17] In Figure 5: If the lines run in parallel, there is no interaction between the two parameters, but if they divert, then there is an interaction.

[18] (a) A. K. d. K. Lewis, S. Caddick, F. G. N. Cloke, N. C. Billingham, P. B. Hitchcock, J. Leonard, J. Am. Chem. Soc. 2003, 125, 10066-10073; (b) J. Pytkowicz, S. Roland, P. Mangeney, G. Meyer, A. Jutand, J. Organomet. Chem. 2003, 678, 166-179; (c) J. C. Green, B. J. Herbert, R. Lonsdale, J. Organomet. Chem. 2005, 690, 6054-6067; (d) S. Roland, P. Mangeney, A. Jutand, Synlett 2006, 3088-3094; (e) A. Jutand, J. Pytkowicz, S. Roland, P. Mangeney, Pure Appl. Chem. 2010, 82, 1393-1402; (f) I. Peñafiel, I. M. Pastor, M. Yus, Eur. J. Org. Chem. 2013, 1479-1484.

[19] (a) J. F. Hartwig, F. Paul, Organometallics 1995, 14, 3030-3039; (b) E. Galardon, S. Ramdeehul, J. M. Brown, A. Cowley, K. K. Hii, A. Jutand, Angew. Chem. Int. Ed. 2002, 41, 1760-1763; (c) E. Galardon, S. Ramdeehul, J. M. Brown, A. Cowley, K. K. Hii, A. Jutand, Angew. Chem. 2002, 114, 1838 1841; (d) J. P. Stambuli, M. Bühl, J. F. Hartwig, J. Am. Chem. Soc. 2002, 124, 9346-9347; (e) I. D. Hills, M. R. Netherton, G. C. Fu, Angew. Chem. 2003, 115, 5927-5930; (f) I. D. Hills, M. R. Netherton, G. C. Fu, Angew. Chem. Int. Ed. 2003, 42, 5749-5752; (g) F. Barrios-Landeros, J. F. Hartwig, J. Am. Chem. Soc. 2005, 127, 6944-6945; (h) F. Barrios-Landeros, B. P. Carrow, J. F. Hartwig, J. Am. Chem. Soc. 2009, 131, $8141-8154$.

[20] A 1:1 metal/ligand ratio was also observed at $420 \mathrm{~nm}$ (see Supporting Information).

[21] X. Wu, J. Zhou, Chem. Commun. 2013, 49, 4794-4796. 